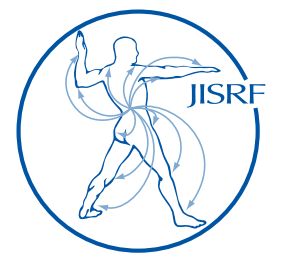

\title{
Modular Head Mismatch in THA
}

\author{
McTighe $T^{1}$ \\ Acknowledgement: \\ This is a case report of two cases from JISRF's Tissue Sparing Study Group. We are grateful for their \\ willingness to share these case examples of femoral head mismatch.
}

\section{Abstract}

Modular femoral heads have been used successfully since the mid-1980s in total hip arthroplasty. The use of metallic modular junctions presents a unique set of advantages and problems for use in total hip arthroplasty (THA). The separation of the head from the stem by a Morse taper has provided many benefits on the precision and balancing the reconstructed joint. Historically few complications have been reported for the modular Morse taper connection between the femoral head and trunnion of the stem in metal-onpolyethylene bearings. However, the risks or concerns are a little harder to identify and deal with. Certainly corrosion, and fatigue failure are the two most prevalent concerns but now the specifics of fretting wear and corrosive wear increasing particulate debris and the potential biological response is having an impact on the design and potential longevity of the reconstructed hip. This paper is dealing with a simpler consequence of head/stem modularity. Modular head mismatch to the socket bearing articulation.

Two patients by two different surgeons at two different hospitals underwent cementless THA. Both patients were female and both presented with degenerative changes to the hip articulation. Both patients underwent hip replacement via a direct anterior approach using a standard hemispherical porous coated shell. One patient had a ceramic on ceramic bearing and the other had a ceramic head on a polyethylene liner. One patient had a $32 \mathrm{~mm}$ inside diameter liner and a $36 \mathrm{~mm}$ ceramic femoral head implanted. The other patient had a $36 \mathrm{~mm}$ inside diameter liner and a $40 \mathrm{~mm}$ ceramic femoral head implanted. The ceramic on ceramic mismatch was not recognized until the second office visit at eight weeks. The ceramic poly mismatch was not recognized until first office visit at six weeks. Both underwent correction surgery.

These two cases demonstrate human mistakes can be made and steps need to be established to prevent future mistakes of this nature.

Keywords: modular head, mismatch, total hip arthroplasty Level of Evidence: AAOS Therapeutic Level IV

1 Timothy McTighe, Dr. HS (hc), Joint Implant Surgery \& Research Foundation, 46 Chagrin Shopping Plaza, \#117, Chagrin Falls, OH 44022 US

(Direct reprint requests to Timothy McTighe)
(C) 2015 McTighe. All rights reserved

Authors retain copyright and grant the journal right of first publication with the work. Reconstructive Review follows the Creative Commons Attribution-NonCommercial CC BY-NC. This license allows anyone to download works, build upon the material, and share them with others for non-commercial purposes as long as they credit the senior author, Reconstructive Review, and the Joint Implant Surgery \& Research Foundation (JISRF). An example credit would be: "Courtesy of (senior author's name), Reconstructive Review, JISRF, Chagrin Falls, Ohio". 


\section{Introduction}

In dealing with the complex problems of THA the use of metallic and ceramic modular heads has proven to be a significant benefit. [1,2] To-date, all current cementless stem designs have one feature in common - a modular head. However not all modular taper junctions are designed equally.

The success of a self-locking taper is influenced by the design of the taper, particularly the taper angle, the roughness, and the mating materials between the "male" and "female" components. This results in co-integration (locking), with material transfer across the zone of contact (cold welds). Figure 1.

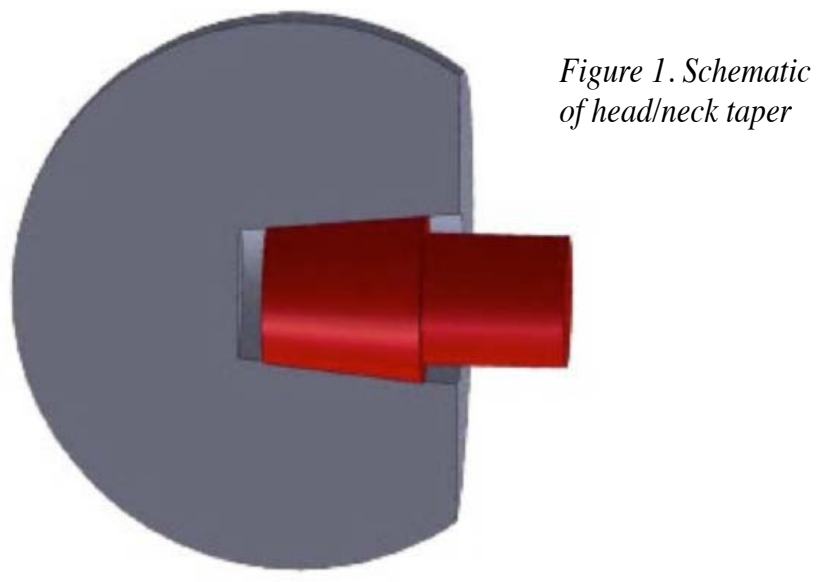

In the last two decades, manufactures have been altering femoral stem trunnions from various tapers such as $14 / 16$ to $12 / 14$ to $11 / 13$. Figure 2 . A range of different Morse taper angles, component tolerances and sizes, and surface finishes exist within commercially available hip systems. While manufacturers do not recommend mixing and matching of component brands, a number of surgeons have been mixing and matching without complications, provided the products used have the same manufacturing tolerances.
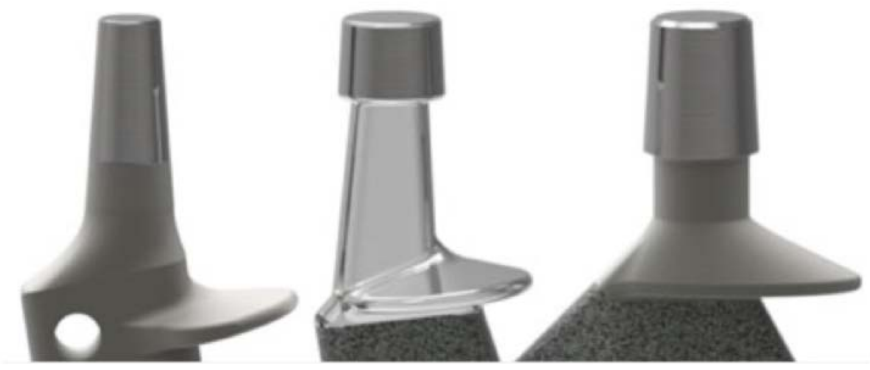

Figure 2. Illustration Showing Different Taper Designs by

Manufacturers. (Courtesy Chris Burgess, Signature Orthopaedics Ltd.)

It is important to remember that early introduction of stem modularity did present problems, including disas- sociation of modular heads, incorrect head diameters implanted, and trunnion fatigue fractures. Figure 3.

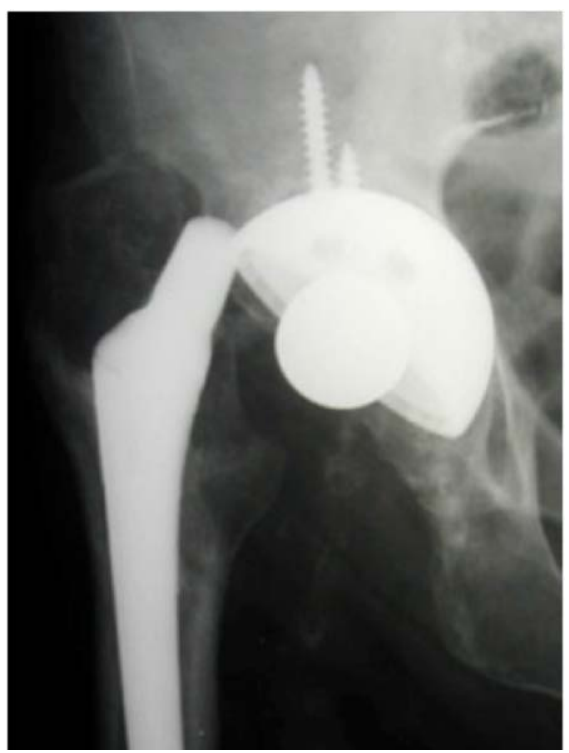

Figure 3. Detachment of modular head can damage stem trunnion. (Curtsey JISRF Archives)

This paper will review two separate case reports of mismatch articulation bearing diameters, one ceramic on ceramic and one ceramic on polyethylene.

\section{Case Reports}

\section{CASE 1}

The patient presented for initial evaluation in her sixth decade with a recent history of progressive right hip pain, stiffness and difficulty with daily activities unresponsive to non-operative measures. On exam she had hip irritability with attempted range of motion and walked with a moderate limp. She had moderate hip stiffness. She had generalized ligamentous laxity. Radiographs showed advanced degenerative changes of the right hip with underlying right hip acetabular dysplasia. Figure 4.

She underwent right hip replacement via a direct anterior approach using a standard porous coated $52 \mathrm{~mm}$ shell with an alumina ceramic liner of $32 \mathrm{~mm}$ inside diameter (S\&N FS05 shell and liner, S\&N ceramic alumina head). Augmentation of the acetabulum was not required, nor was additional screw fixation. On the femoral side a titanium neck-sparing, proximally porous coated small curved stem (ARC ${ }^{\circledR}$ by OmniLife) was implanted securely. This stem allowed modular options for hip reconstruction. A short, $8^{\circ}$ varus cobalt chrome modular neck component was selected and impacted in place. The alumina ceramic femoral head component was impacted securely in place. The hip demonstrated good stability and limb length. She had an uneventful postoperative course with rapid mobilization and return of function. 


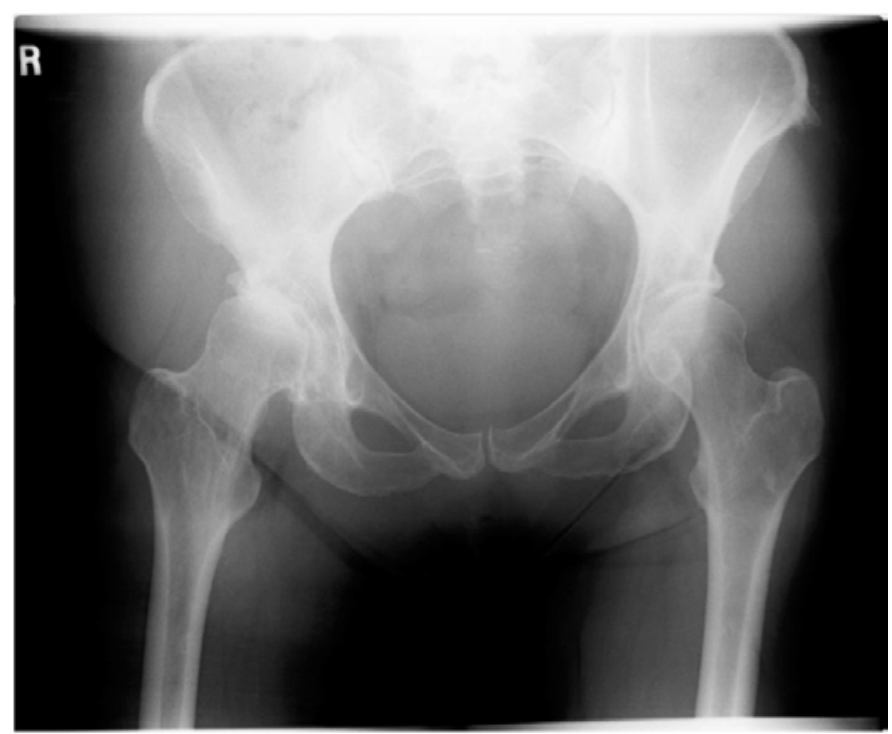

Figure 4. Radiographs showed advanced degenerative changes of the right hip with underlying right hip acetabular dysplasia.

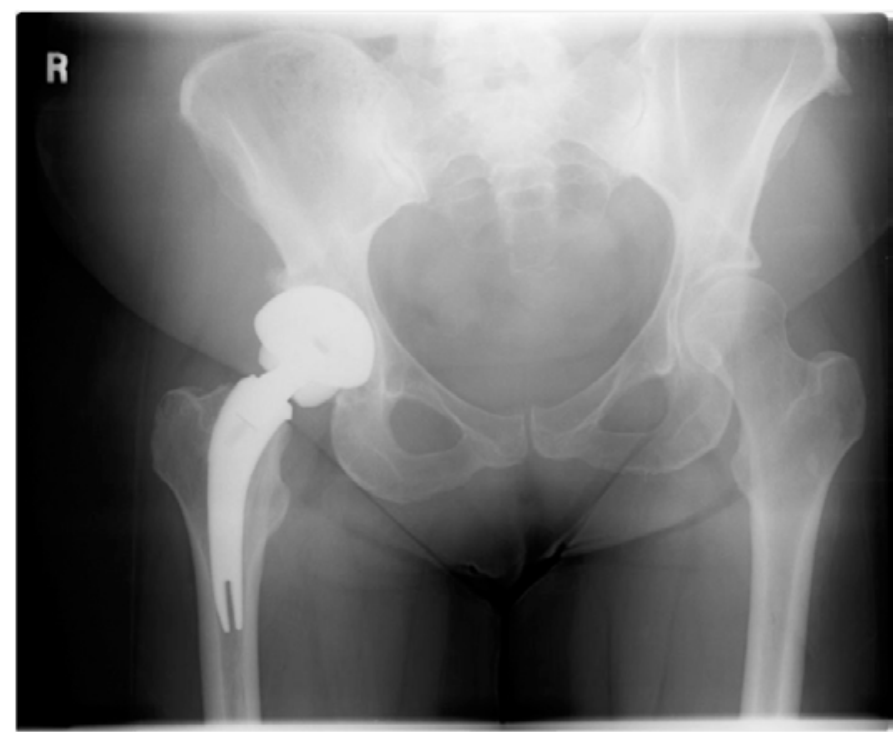

Figure 5. Mismatch head bearing diameter (36 mm ceramic head \& $32 \mathrm{~mm}$ ceramic bearing liner)

She presented to the office for follow-up at three weeks with no difficulties. At eight weeks she reported a new grating sensation in the right hip without trauma. She had no significant pain and no complaints of a neurovascular nature. Radiograph revealed no evidence of ceramic fracture but a diameter mismatch of the femoral head and acetabular liner components. Review of the implant log revealed implantation of a $36 \mathrm{~mm}$ outside diameter had component with a $32 \mathrm{~mm}$ inside diameter acetabular liner. Figure 5.

She returned to the operating room for revision surgery which included acetabular liner exchange and exchange of the modular neck and femoral head component. The neck was replaced with identically sized implant. The femoral head component was changed to a $32 \mathrm{~mm}$ outside diameter medium length alumina ceramic head. This combination maintained leg length and provided good stability. Again, she had an uneventful postoperative course. Acetabular shell and femoral stem components were noted to be well fixed and well positioned.

\section{CASE 2}

The patient presented for initial evaluation at the beginning of her 6th decade with a several year history of progressive right hip pain, stiffness. She had failed conservative measures including injections, oral anti-inflammatories, and activity modifications. On exam she had hip pain with attempted range of motion, a 10 degree hip flexion contracture and walked with a moderate antalgic gait. Radiographs showed advanced degenerative changes of the right hip with cystic degeneration on both sides of the joint.

She underwent right hip replacement via a direct anterior approach using a standard porous coated plasma spray $52 \mathrm{~mm}$ shell (Biomet RingLoc+) with a neutral offset highly cross-linked vitamin E polyethylene liner of $36 \mathrm{~mm}$ inside diameter. Augmentation of the acetabulum was not required, nor was additional screw fixation. On the femoral side titanium neck sparing, proximally porous coated small curved stem (\#2 Omni-ARC), was implanted securely. This stem allowed modular options for hip reconstruction. A short, $12^{\circ}$ varus cobalt chrome modular neck component was selected and impacted in place. An alumina ceramic femoral head component was impacted in place. The hip demonstrated excellent stability with excellent restoration of limb length and offset as assessed both clinically and with intraoperative fluoroscopy (fluoroscopy used at trial component stage only). She had a normal postoperative course.

She presented to the office at 2 weeks having transitioned to a cane at one week. She presented at 6 weeks complaining of mild persistent pain. Radiograph revealed no evidence of ceramic fracture. Component position was felt to be excellent but a diameter mismatch of the femoral head and acetabular liner was suspected due to subtle asymmetry of the head and acetabula shell. Review of the implant log revealed implantation of a $40 \mathrm{~mm}$ outside diameter head component with a $36 \mathrm{~mm}$ inside diameter acetabula liner. Figure 6.

She returned to the operating room for revision. Acetabular shell and femoral stem components were noted to be well fixed and well positioned. The femoral head component was changed to a 36-+4-alumina ceramic. The modular neck and polyethylene liner were retained. This combination maintained good leg length and provided good stability. Again, she had an uneventful postoperative course. 


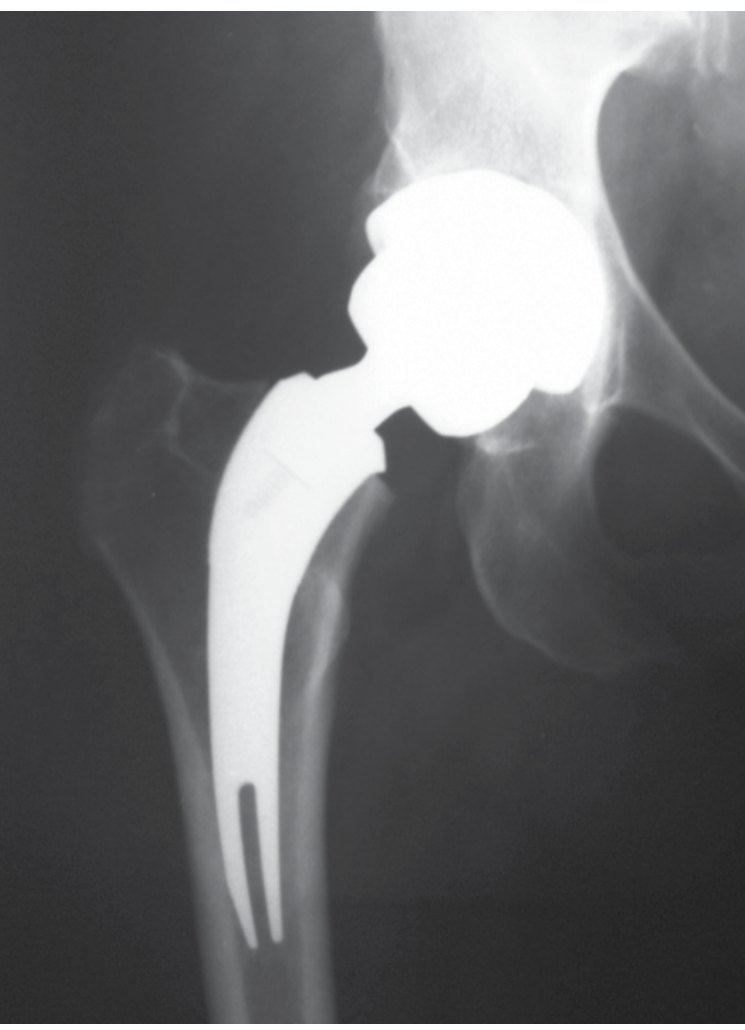

Figure 6. Mismatch head bearing diameter $40 \mathrm{~mm}$ head \& $36 \mathrm{~mm}$ bearing liner)

\section{Conclusion}

These two separate case reports dealing with the same intraoperative errors clearly demonstrated that the best high technology devices are only as good as the surgical technique and surgical skills of the operating surgeon at the time of implantation. "Technique, Technique, Technique is more important than design or material" an old quote by David Hungerford, MD.

We have seen time out established prior to surgical incision to reduce errors and the surgeons along with their institutions recommend a formal implant time out at each stage of the procedure.

Both surgeons should be commended for as soon as they recognized the error they informed their patients and re-operated to correct the problem while it was still a minor situation.

\section{References}

1. McTighe T, Brazil D, Bruce W. Metallic Alloys in Total Hip Arthroplasty. In book: The Hip: Preservation, Replacement, and Revision, Chapter: Chapter 14 Metallic Alloys in Total Hip Arthroplasty, Publisher: Data Trace Publishing Company, Editors: Javad Parvizi, Nitin Goyal, James Cashman, pp.14-1 to 14-12 [CrossRef]

2. McTighe T, Brazil D, Clarke I, et al. Metallic Modular Taper Junctions in Total Hip Arthroplasty. Reconstructive Review · August 2015 [CrossRef]

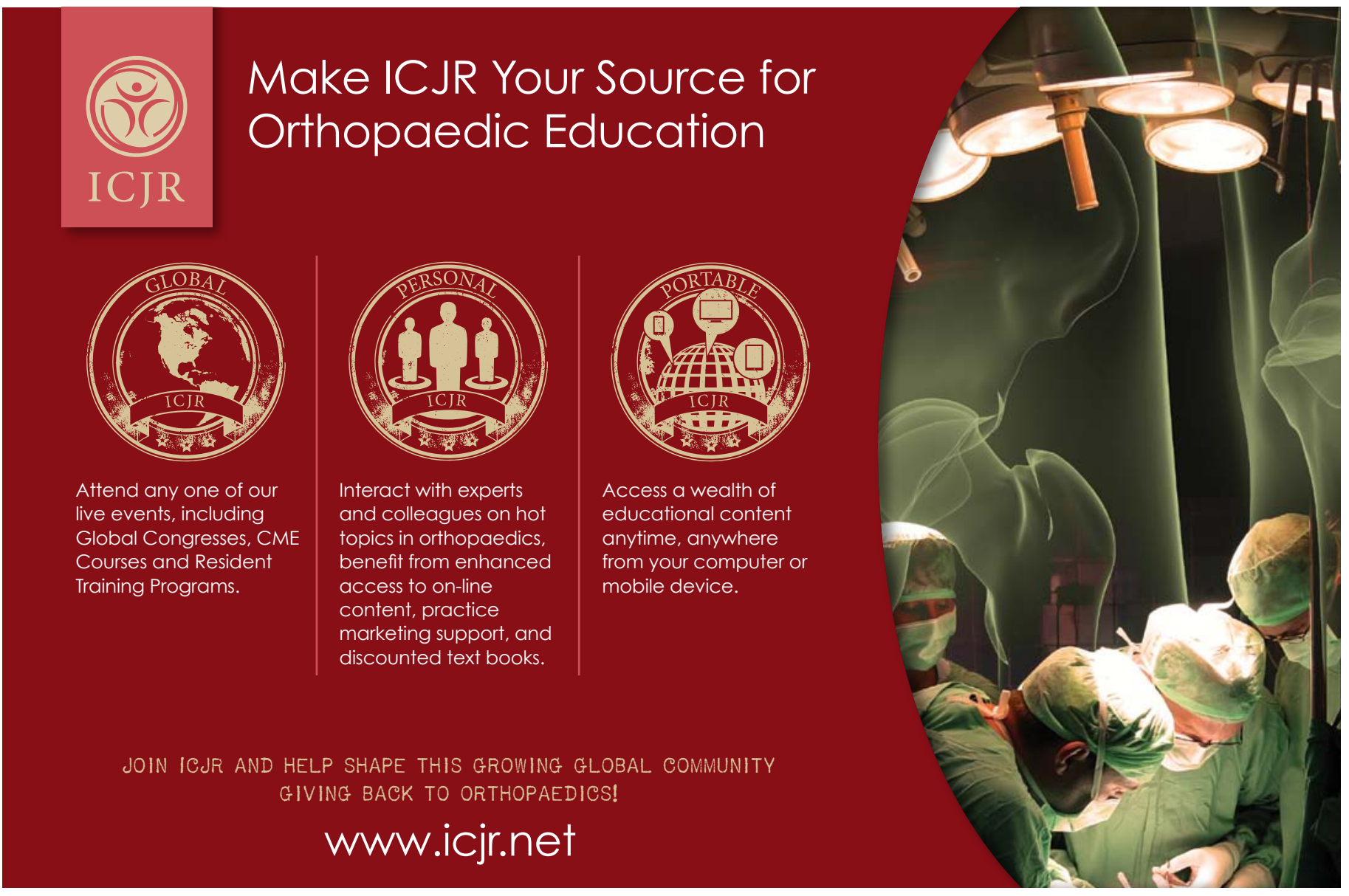

